\title{
Pulmonary vagal modulation of ventilation in toads (Bufo marinus)
}

\author{
Stephen G. Reid ${ }^{\mathrm{a}, *}$, William K. Milsom ${ }^{\mathrm{b}}$, Janice T. Meier ${ }^{\mathrm{b}}$, Suzy Munns ${ }^{\mathrm{b}}$, \\ Nigel H. West ${ }^{\text {a }}$
}

a Department of Physiology, College of Medicine, University of Saskatchewan, 107 Wiggins Road, Saskatoon SK, Canada S7N 5E5

${ }^{\mathrm{b}}$ Department of Zoology, University of British Columbia, Vancouver BC, Canada V6T $1 Z 4$

Accepted 13 December 1999

\begin{abstract}
This study examined the role of pulmonary vagal feedback on hypercapnic chemosensitivity and breathing pattern formation in cane toads (Bufo marinus). Decerebrate, paralysed toads were uni-directionally ventilated with air, $2.5 \%$ $\mathrm{CO}_{2}$ or $5.0 \% \mathrm{CO}_{2}$ with the lungs inflated or deflated, before and after pulmonary vagotomy. Motor output from the mandibular branch of the trigeminal nerve served as an index of fictive breathing. As respiratory drive was increased, breathing frequency increased and breaths were clustered into discrete episodes separated by periods of apnea. Lung deflation tended to enhance episodic breathing while inflation biased the system towards apnea at low levels of respiratory drive and a pattern of continuous, small breaths at higher levels of respiratory drive. Following bilateral pulmonary vagotomy there was no increase in ventilation during hypercapnia and lung inflation/deflation had no effect on breathing pattern. In isolated brainstem-spinal cord preparations from the same animals, all variables associated with fictive breathing were unaffected by changes in superfusate $\mathrm{pH}$ from 8.0 to 7.6 . The breathing pattern from the in vitro preparations was highly variable. This study demonstrates a crucial role for vagal feedback in modulating respiration and the respiratory responses to hypercapnia in B. marinus. (C) 2000 Elsevier Science B.V. All rights reserved.
\end{abstract}

Keywords: Amphibians, toad (Bufo marinus); Chemosensitivity, central; $\mathrm{CO}_{2}$, central response; Control of breathing, central chemosensitivity; Vagus nerve, feedback, pattern of breathing

\section{Introduction}

The role of peripheral sensory feedback in the regulation of respiratory rhythm and pattern for-

\footnotetext{
* Corresponding author. Tel.: + 1-306-9666543; fax: + 1306-9666532.

E-mail address: reidsg@hotmail.com (S.G. Reid)
}

mation in anuran amphibians is not well understood. There are a large number of inputs, both intrinsic to the brain and from sensory receptors, that interact to determine respiratory rate, rhythm and pattern in vertebrates (see reviews by Milsom, 1991; West and Van Vliet, 1992; Kinkead, 1997). These inputs include feedback from central (Smatresk and Smits, 1991; Branco et al., 1992; 
Kinkead et al., 1994; McLean et al., 1995a,b; Torgerson et al., 1997) and peripheral chemoreceptors (West et al., 1987; Smatresk and Smits, 1991; Kinkead and Milsom, 1994), lung stretch receptors (Kinkead and Milsom, 1996, 1997), descending influences from higher brain centers to the respiratory sites located in the brainstem (Kinkead et al., 1997; Milsom et al., 1997), as well as mechanisms intrinsic to the brainstem itself (Ito and Watanabe, 1962; Kogo et al., 1994; Kogo and Remmers, 1994; McLean et al., 1995a,b; Galante et al., 1996; Kimura et al., 1997; Liao et al., 1996; Milsom et al., 1997; Reid and Milsom, 1998).

Pulmonary stretch receptors (PSR) send information to the brainstem through the pulmonary vagi. Afferent traffic increases with lung inflation and decreases with lung deflation. In adult anurans, PSR are also $\mathrm{CO}_{2}$ sensitive. Their firing rates decrease as intrapulmonary $\mathrm{CO}_{2}$ concentration increases (Milsom and Jones, 1977; Kuhlmann and Fedde, 1979). One of the most important interactions between sensory inputs is the one between chemoreceptor input, providing a source of tonic chemical drive, and phasic input from pulmonary stretch receptors (e.g. Kinkead et al., 1994).

Currently, there are conflicting observations and interpretations of the role of PSR feedback in amphibians. Kogo et al. (1994) found that in decerebrate, paralysed and uni-directionally ventilated bullfrogs, lung deflation (which decreases PSR activity) generally increased breathing frequency while vagotomy (which totally removes all PSR feedback) caused a decrease in breathing frequency. Kinkead and Milsom (1997), on the other hand, found that both lung deflation and vagotomy decreased the frequency and increased the amplitude of fictive breathing in bullfrogs. Thus, in the latter study, both vagotomy and lung deflation tended to potentiate, rather than inhibit, ventilatory activity at any level of chemoreceptor drive while in Kogo et al. (1994), the effects of removing PSR feedback differed depending on whether it was removed by vagotomy or lung deflation.

Consistent with the data of Kinkead and Milsom (1997) is the observation that the increase in breathing frequency recorded from in vitro brain- stem-spinal cord preparations of Rana, in response to a fall in superfusate $\mathrm{pH}$, is blunted compared to the responses to hypercapnia in the decerebrate, paralyzed preparation and in intact animals (Kinkead et al., 1994; McLean et al., 1995a,b; Kinkead and Milsom, 1996; Reid and Milsom, 1998). However, in the in vitro preparation, the response to changes in superfusate $\mathrm{pH}$ are enhanced when vagal feedback, presumably simulating lung inflation, is provided (Kinkead et al., 1994) just as it was in the study of Kogo et al. (1994). To add to the confusion, Wang et al. (1999) have recently shown that in another anuran, the cane toad (Bufo marinus), lung deflation increases breathing frequency while inflation reduces breathing frequency and that increasing levels of $\mathrm{CO}_{2}$ enhance the effects of lung deflation.

Given (1) the conflicting evidence about the effects of lung inflation/deflation; (2) the potential differences between removal of PSR feedback by lung deflation and vagotomy; (3) differences between in situ and in vitro preparations, and (4) questions about the nature of the interaction between feedback from lung stretch receptors and $\mathrm{CO}_{2} / \mathrm{pH}$ chemoreceptors, the goals of this study were to further investigate the ventilatory response to hypercapnia in the cane toad (B. mari$n u s$ ) and its modulation by both pulmonary vagal feedback and the level of reduction of the preparation. To this end, we investigated the effect of lung inflation/deflation and pulmonary vagotomy on the respiratory motor output of the in situ brainstem in a decerebrate, paralysed UDV preparation in which $\mathrm{Pa}_{\mathrm{CO}_{2}}$ and $\mathrm{pHa}$ were varied. The results were compared with the motor output of the same brainstem, superfused in vitro over a similar range of superfusate $\mathrm{pH}$.

\section{Materials and methods}

\subsection{General}

\subsubsection{Experimental animals}

Toads (B. marinus) ( $\approx 250 \mathrm{~g} ; N=13)$ were obtained from a commercial supplier (Cyr's Biological, Louisiana). Animals were maintained in 
fiberglass tanks supplied with a constant flow of dechlorinated City of Vancouver tapwater to provide a moist environment. A heating lamp above the tanks maintained the temperature at approximately $30^{\circ} \mathrm{C}$. The photoperiod was maintained at 12L:12D. Toads were fed live locusts at least once a week. The animals were allowed to acclimate to laboratory conditions for a minimum of 2 weeks before the experiments were performed.

\subsubsection{Anaesthesia and decerebration}

Cane Toads were anaesthetized by partial submersion in an aqueous solution of ethyl-maminobenzoate (MS 222; $0.6 \mathrm{~g} \mathrm{~L}^{-1}$ ) buffered to pH 7.0 with sodium bicarbonate. A surgical plane of anesthesia (i.e. the animal no longer exhibited any response to toe pinching or touching the eyes) was obtained in $\approx 30 \mathrm{~min}$. The skin and cranial case, rostral to the optic lobes, were carefully removed using a dental drill until only a thin layer of bone remained. The remaining bone was then removed with bone shears. The brain, rostral to the optic lobes, was exposed and the rostral forebrain was removed using an electrocautery to simultaneously transect the tissue and control bleeding, and suction to aspirate the forebrain tissue from the braincase. The rostral regions of the skull were then packed with cotton and the braincase sealed with dental dam and tissue adhesive. The toad was then allowed to recover from the effects of anesthesia for 24-48 $\mathrm{h}$ before experimentation.

\subsection{In Situ experiments}

\subsubsection{Paralysis}

Twenty-four to forty-eight hours following decerebration, toads were paralyzed by an injection of rocuronium bromide (Organon Biochemicals; $0.1 \mathrm{ml} 100 \mathrm{~g}^{-1}$ body weight) into the dorsal lymph sacs. Rocuronium is exceptionally fast acting with paralysis occurring in $<2 \mathrm{~min}$. Additionally, it has no adverse effects on the cardiovascular system allowing for the maintenance of normal systemic pressure during experimentation.

\subsubsection{Cannulations}

Following paralysis, the lung apices were cannulated (PE 160 tubing) according to the method described by West et al., (1987) to permit unidirectional ventilation (UDV) of the lungs. It was therefore possible to change the composition of the lung gas during experimentation by changing the unidirectional ventilating gas mixture. The glottis was sealed with tissue adhesive to prevent the escape of lung gas during UDV. Given that the animal was paralyzed, ventilatory drive did not result in movement of the buccal force pump.

The left femoral artery was cannulated with a polyethylene cannulae (PE 50 tubing) filled with heparinized saline $(100 \mathrm{IU} \mathrm{ml} ; 0.65 \% \mathrm{NaCl})$ to record blood pressure/heart rate and to sample arterial blood to measure blood gases and $\mathrm{pH}$.

Following these measurements, the blood sample was returned to the animal to prevent a decrease in haematocrit.

\subsubsection{Nerve exposure and recording}

2.2.3.1. Trigeminal nerve. The skin covering the mandible was cut and retracted to expose the mandibular branch of the trigeminal nerve. The nerve was dissected free of its associated connective tissue, cut peripherally and immediately covered in a mixture of mineral oil and Vaseline $(1: 1)$ to prevent desiccation. The isolated branch of the trigeminal nerve was placed over a bipolar hook electrode and covered with the mineral oil/Vaseline mix. The mandibular branch of the trigeminal nerve innervates buccal elevator muscles that are active during both lung ventilation and small amplitude buccal oscillations (Sakakibara, 1984a,b). Electrical activity recorded from this nerve represents either fictive lung ventilation or fictive buccal oscillations (Kogo et al., 1994). The designation of motor output as a fictive breath was based on comparisons with previous studies utilising this preparation (e.g. Kinkead and Milsom, 1997).

Trigeminal motor nerve activity from the bipolar hook electrode was amplified, filtered (filter settings: $50 \mathrm{~Hz}$, high pass; $10 \mathrm{kHz}$, low pass), full wave rectified and integrated. The signal was monitored visually using an oscilloscope (Tek- 
tronix 511A) and acoustically with an audio monitor (Grass AM8). Activity was recorded on a chart recorder (Gould) and representative recordings were saved using a data acquisition system (Windaq, DataQ Systems). The sampling rate of analogue to digital conversion was $2000 \mathrm{~Hz}$.

2.2.3.2. Pulmonary vagus. To identify the pulmonary branch of the vagus nerve $(\mathrm{X})$ for subsequent bilateral vagotomy, a $2 \mathrm{~cm}$ axillary incision was made behind each scapula. The underlying musculature was reflected by blunt dissection to expose the rostral end of the lung. The pulmonary branch of the vagus nerve was identified at the level of the lung hilus. The nerve was carefully freed from the associated pulmonary vessels and a loop of surgical silk (000 gauge) was placed around the nerve and exteriorized through the incision to facilitate identification at the appropriate time in the experiment. The muscle and skin layers were separately sutured in order to close the incision.

\subsubsection{UDV and measurement of arterial blood pressure and heart rate}

Following surgery (cannulation and nerve exposure), the lungs were unidirectionally ventilated (300-400 $\mathrm{ml} \mathrm{min}^{-1}$ ) with air. Before entering the lungs, the inflowing gas was humidified by bubbling through an Erlenmeyer flask half filled with water. In these experiments the animal was ventilated with either air, $2.5 \% \mathrm{CO}_{2}$ in air or $5.0 \% \mathrm{CO}_{2}$ in air. The gas mixtures used to ventilate the animal were produced by mixing air and $\mathrm{CO}_{2}$ with flow meters. Levels of $\mathrm{CO}_{2}$ entering the lungs were routinely monitored with a mass spectrometer.

Intrapulmonary pressure, and therefore the degree of lung inflation, was controlled by placing the tip of the outflow cannula into a beaker of water in order to provide an outflow resistance of $4 \mathrm{~cm} \mathrm{H}_{2} \mathrm{O}$. The lungs were well inflated at this level of outflow resistance. In order to deflate the lungs, the outflow cannula was removed from the water.

The arterial cannula was attached to a pressure transducer to record arterial blood pressure. The pressure transducer was calibrated with a static water column $(40 \mathrm{~cm})$. Arterial blood pressure was recorded with both a chart recorder and a computer data acquisition system (Windaq, Data Q Systems).

\subsubsection{Experimental protocols}

2.2.5.1. The effects of altering $P_{\mathrm{CO}_{2}}$ and lung volume. Toads were ventilated with air for a minimum of $15 \mathrm{~min}$ with the lungs inflated (i.e. $4 \mathrm{~cm}$ $\mathrm{H}_{2} \mathrm{O}$ outflow resistance) before recording. Following this stabilisation period, fictive breathing and arterial blood pressure/heart rate were recorded for a period of $5 \mathrm{~min}$. The lungs were then deflated and, following a $15 \mathrm{~min}$ equilibration period, the cardiorespiratory variables were recorded for $5 \mathrm{~min}$.

The above protocol examined the chronic effects of lung inflation or deflation on fictive ventilation and arterial blood pressure/heart rate. To test for phasic effects, the lungs were rapidly inflated and deflated two to three times over approximately a $1 \mathrm{~min}$ period by rapidly removing and adding the outflow resistance. One minute after the termination of these rapid changes, an arterial blood sample $(0.7 \mathrm{ml})$ was withdrawn to measure the arterial partial pressure of oxygen $\left(\mathrm{Pa}_{\mathrm{O}_{2}}\right)$ and carbon dioxide $\left(\mathrm{Pa}_{\mathrm{CO}_{2}}\right)$ as well as arterial $\mathrm{pH}(\mathrm{pHa})$.

The above protocol was repeated with UDV gas mixtures of 2.5 and $5.0 \% \mathrm{CO}_{2}$. In each case the toad was allowed to equilibrate to the new gas mixture for at least 15 min before recordings were made.

2.2.5.2. The effect of bilateral pulmonary vagotomy. Following the above protocol, the pulmonary vagus nerve on each side was exposed via the axillary incision. The loop of surgical silk was knotted around the nerve and the nerve severed peripheral to the knot. The experimental protocol was then repeated to examine the effect of removing pulmonary vagal feedback on the cardiorespiratory responses to hypercapnia and lung inflation/deflation.

Once the in situ experiments were complete, the lungs were filled with oxygen and held inflated by sealing the UDV cannulae. The decerebrate toad 
was then placed in a humidified chamber $\left(4^{\circ} \mathrm{C}\right)$ until the next day when the brainstem was removed for use in the in vitro experiments. In no instance did the effects of the paralytic agent wear off over night.

\subsection{In vitro experiments}

\subsubsection{In vitro brainstem-spinal cord preparation}

The dental dam covering the brain was removed, and the brain was continually perfused with oxygenated, bicarbonate-buffered Ringers (mmol L-1: $\mathrm{NaCl}, 75.0 ; \mathrm{KCl}, 4.5 ; \mathrm{MgCl}_{2}, 1.0$; $\mathrm{NaH}_{2} \mathrm{PO}_{4}, 1.0 ; \mathrm{NaHCO}_{3}, 40.0 ; \mathrm{CaCl}_{2}, 2.5$; glucose, 5.0; pH 8.0). A pH of 8.0 was selected as it approximates the arterial $\mathrm{pH}$ of these animals during the in situ experiments when they were unidirectionally ventilated with air (Table 1).

Cranial nerves were cut close to their exit from the skull and the spinal cord was severed at the level of the second spinal nerve. The brainstemspinal cord was removed from the skull and pinned in a dissecting dish where the membranes were removed to free the cranial nerve roots. The preparation was then pinned, ventral side up, on a fine stainless steel mesh within a superfusion chamber. The mesh divided the chamber into upper and lower compartments, which facilitated constant perfusion of the entire surface of the brain (Kinkead et al., 1994; McLean et al., 1995a,b). Once the brainstem-spinal cord was secure within the chamber the preparation was superfused, at $5 \mathrm{ml} \mathrm{min}-1$ for $1 \mathrm{~h}$ to allow it to stabilize (Reid and Milsom, 1998). All experiments were performed at room temperature.

\subsubsection{Fictive breathing}

A suction electrode, made from thin-walled capillary glass (inner diameter $1 \mathrm{~mm}$ ) was positioned near the end of the severed trigeminal nerve using a micro-manipulator. The nerve rootlet was gently aspired into the electrode. Care was taken to ensure that the nerve fitted tightly into the electrode permitting the formation of a good electrical seal. Once the nerve rootlet was firmly in place within the electrode, whole nerve discharge (motor output) was recorded as an index of fictive breathing (see below). Trigeminal nerve activity from the suction electrode was amplified, filtered and recorded as above.

In the in vitro experiments, the classification of neural discharge as a fictive breath was based on (1) comparison of the in vitro motor output to fictive breathing obtained in the in situ preparations and (2) the criteria for fictive breathing described by Reid and Milsom (1998). Briefly, fictive breaths were $<1 \mathrm{sec}$ in duration and exhibited an incrementing ('ramplike') onset followed by a similar decrementing offset.

Neural discharge longer than one second and/ or exhibiting different forms of onset and/or offset was not considered to be a normal fictive breath (Reid and Milsom, 1998).

\subsubsection{Experimental protocol}

Nerve discharge was observed in these preparations within 1 hour post-dissection. The start of neural discharge was followed by a 15 min equilibration period at $\mathrm{pH}$ 8.0. Fictive breathing was then recorded for a period of $10 \mathrm{~min}$. The $\mathrm{CO}_{2}$ concentration in the superfusion reservoir was

Table 1

Arterial blood gases and $\mathrm{pH}$ during UDV with air, 2.5\% $\mathrm{CO}_{2}$ and $5 \% \mathrm{CO}_{2}$ in toads, B. marinus ${ }^{\mathrm{a}}$

\begin{tabular}{llll}
\hline & Air & $2.5 \% \mathrm{CO}_{2}$ & $5 \% \mathrm{CO}_{2}$ \\
\hline $\mathrm{Pa}_{\mathrm{O}_{2}}$ (Torr) & $114.3 \pm 5.3 N=13, n=24$ & $121.5 \pm 2.7, N=13, n=22$ & $123.9 \pm 2.9, N=13, n=23$ \\
$\mathrm{~Pa}_{\mathrm{CO}_{2}}$ (Torr) & $6.2 \pm 0.4, N=13, n=28$ & $20.2 \pm 0.9, N=13, n=15$ & $32.3 \pm 1.1, N=13, n=23$ \\
$\mathrm{pHa}$ & $8.12 \pm 0.05, N=7, n=21$ & $7.66 \pm 0.03, N=7, n=15$ & $7.74 \pm 0.04, N=7, n=10$ \\
\hline
\end{tabular}

${ }^{\text {a }} \mathrm{N}$ is the number of animals, $n$, is the number of observations. Values are reported as the mean $\pm 1 \mathrm{~S}$.E.M. The Pa $\mathrm{O}_{2}$ values do not differ from each other while all of the $\mathrm{Pa}_{\mathrm{CO}_{2}}$ and $\mathrm{pHa}$ values differ from one another. 


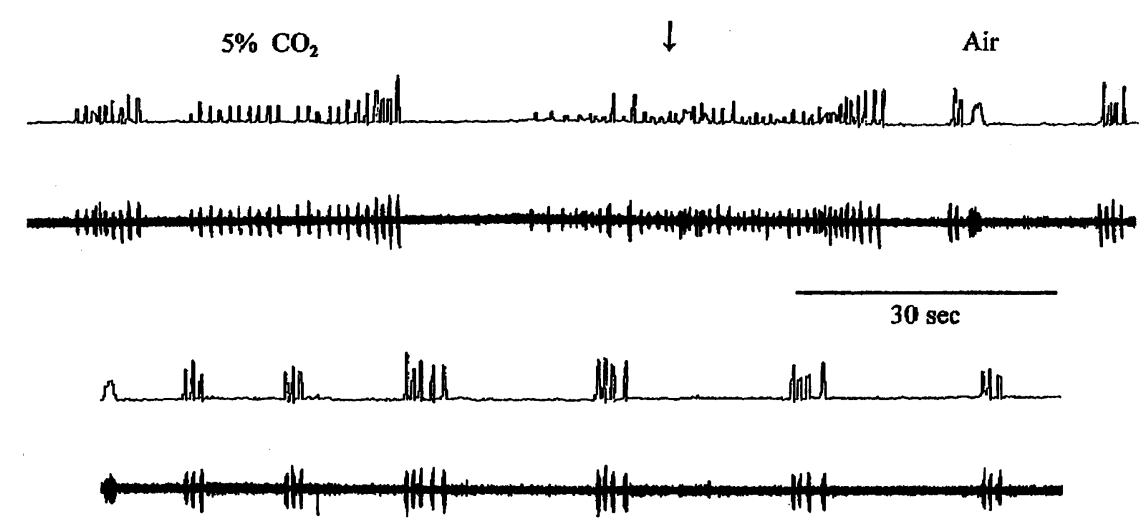

Fig. 1. The effects of unidirectional ventilation with air and $5.0 \% \mathrm{CO}_{2}$ in the in situ preparation. In both panels, the upper trace represents the integrated nerve signal ( $\int$ eng) while the lower trace represents the raw nerve signal (eng). In this figure the toad was initially ventilated with $5.0 \% \mathrm{CO}_{2}$ (left side of the upper panel) before ventilation with air (initiated at the arrow in the upper panel and continued in the lower panel). Note that the switch from $5.0 \% \mathrm{CO}_{2}$ to air converted the breathing pattern from one consisting of large episodes with many breaths into an episodic pattern with relatively evenly spaced episodes containing fewer breaths.

then increased, causing the $\mathrm{pH}$ of the superfusate Ringers to decrease from 8.0 to 7.8 and then to 7.6. Fictive breathing was then recorded, following the appropriate equilibration period, with the $\mathrm{pH}$ of the superfusate set at either 7.8 or 7.6 . These $\mathrm{pH}$ levels were selected to approximate the fall in arterial $\mathrm{pH}$ seen during UDV with $2.5 \%$ $(\mathrm{pHa}=7.7)$ and $5 \% \mathrm{CO}_{2}(\mathrm{pHa}=7.5)$. The $\mathrm{pH}$ of the mock CSF was measured with a $\mathrm{pH}$ meter/ electrode with the electrode positioned in the superfusate reservoir.

\subsection{Data analysis}

Breathing episodes were designated according to the criteria of Kinkead and Milsom (1997). The number of breaths within an episode was obtained by counting the number of successive fictive breaths that occurred with no intervening pause longer than the length of two ventilation cycles. Consequently, when breathing was continuous, no values were obtained for breaths per episode or episodes per minute. Breathing frequency was quantified by analyzing the number of fictive breaths per unit time (absolute frequency; breaths $\left.\min ^{-1}\right)$. The inverse of the period between two successive, uninterrupted breaths within an episode was multiplied by 60 to obtain the instantaneous frequency (breaths/min).

\subsection{Statistical analysis}

The data are presented as the mean \pm 1 standard error of the mean (SEM). Where appropriate, the data were statistically analyzed by either a parametric analysis of variance (ANOVA) followed by Dunnet's multiple comparison test or a two sample $t$-test. When parametric test assumptions were violated, the data were analyzed using a Kruskal-Wallis ANOVA on ranks or a rank sign $t$-test. All statistical testing, including determinations of normality and variance, was performed using commercial software (Sigmastat; Jandel Scientific). The fiducial limit of significance was set at $5 \%$.

\section{Results}

\subsection{In situ experiments}

\subsubsection{Effects of UDV on blood gases/pH}

The arterial blood gas values $\left(\mathrm{Pa}_{\mathrm{O}_{2}}\right.$ and $\left.\mathrm{Pa}_{\mathrm{CO}_{2}}\right)$ and $\mathrm{pH}$, during UDV with air and $\mathrm{CO}_{2}$ (2.5 and $5.0 \%$ ), are reported in Fig. 1. A progressive elevation in the $\mathrm{CO}_{2}$ level within the UDV gas mixture did not change $\mathrm{Pa}_{\mathrm{O}_{2}}$. The change from air to 5.0\% $\mathrm{CO}_{2}$, caused an increase in $\mathrm{Pa}_{\mathrm{CO}_{2}}$ from $\approx 6$ to 32 Torr while pHa decreased from 8.1 to 7.5. 


\subsubsection{Fictive breathing: UDV and pulmonary} vagotomy

Figs. 1 and 2 illustrate several examples of fictive breathing under various conditions of UDV (different gas mixtures) with the pulmonary vagi either intact or transected. The effects on fictive ventilation of the various combinations of UDV gas mixtures (air, $2.5 \% \mathrm{CO}_{2}$ or $5.0 \% \mathrm{CO}_{2}$ ), lung volume (inflated or deflated) and lung innervation (pulmonary vagus intact or transected) are quantified and described in further detail below with emphasis on $\mathrm{CO}_{2}$ chemosensitivity and breathing pattern.

In Fig. 1, when the animal was ventilated with $5.0 \% \mathrm{CO}_{2}$, breathing occurred in long episodes. Following a switch to air (arrow in Fig. 1), respiratory drive decreased and the breathing episodes decreased in frequency as did the number of breaths in each episode leading to a decrease in the absolute frequency of ventilation. In Fig. 2, when the pulmonary vagus was intact, ventilation increased substantially when the UDV gas mix- ture was changed from air to $5.0 \% \mathrm{CO}_{2}$ (upper two traces). In this animal, pulmonary vagotomy (bottom two traces) reduced ventilation to such a degree that the animal became apneic during UDV with air and breathed only occasionally on $5 \% \quad \mathrm{CO}_{2}$ (see below for further details and quantification).

\subsubsection{Effects of lung inflation/deflation and pulmonary vagotomy on $\mathrm{CO}_{2}$ chemosensitivity}

Fig. 3 illustrates the effects of elevating respiratory drive (increased $\mathrm{CO}_{2}$ ), lung inflation/deflation and pulmonary vagotomy on ventilation frequency, amplitude and total ventilation. With the pulmonary vagi intact (Fig. 3A), UDV with both levels of $\mathrm{CO}_{2}$ caused an increase in absolute breathing frequency (breaths/min) under conditions of both lung inflation (open bars) and deflation (solid bars). During UDV with $\mathrm{CO}_{2}$, absolute ventilation frequency was also less when the lungs were deflated versus inflated although this was only statistically significant with $5.0 \%$

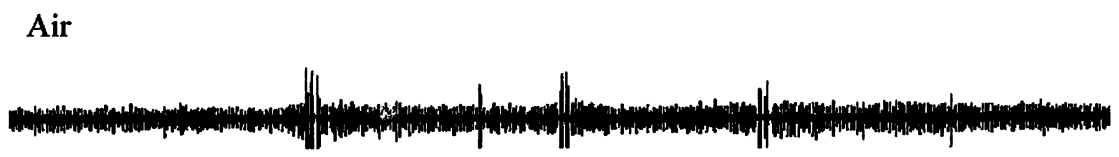

$5 \% \mathrm{CO}_{2}$

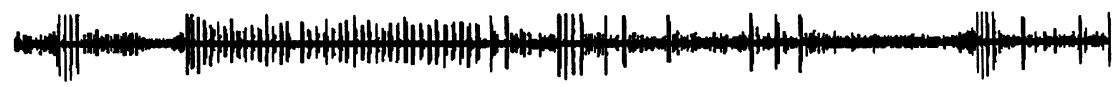

Air

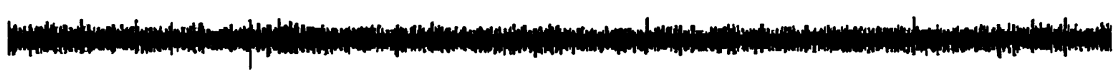

$5 \% \mathrm{CO}_{2}$

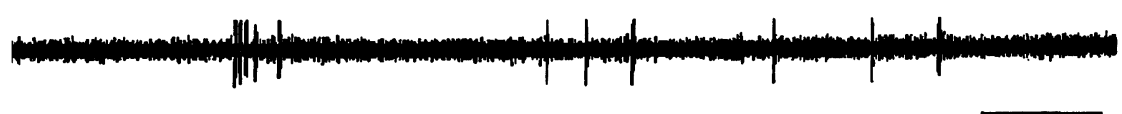

$30 \mathrm{sec}$

Fig. 2. The effects of pulmonary vagotomy on $\mathrm{CO}_{2}$ chemosensitivity. (Upper 2 traces) With the pulmonary vagus intact (upper panel), a change in the UDV from air to $5.0 \% \mathrm{CO}_{2}$ caused a substantial increase in fictive breathing. (Lower 2 traces) Following pulmonary vagotomy (lower panel), breathing was reduced, compared with the intact state, when the animal was subjected to UDV with either air or $5.0 \% \mathrm{CO}_{2}$. Note, in this case the lungs were deflated. 

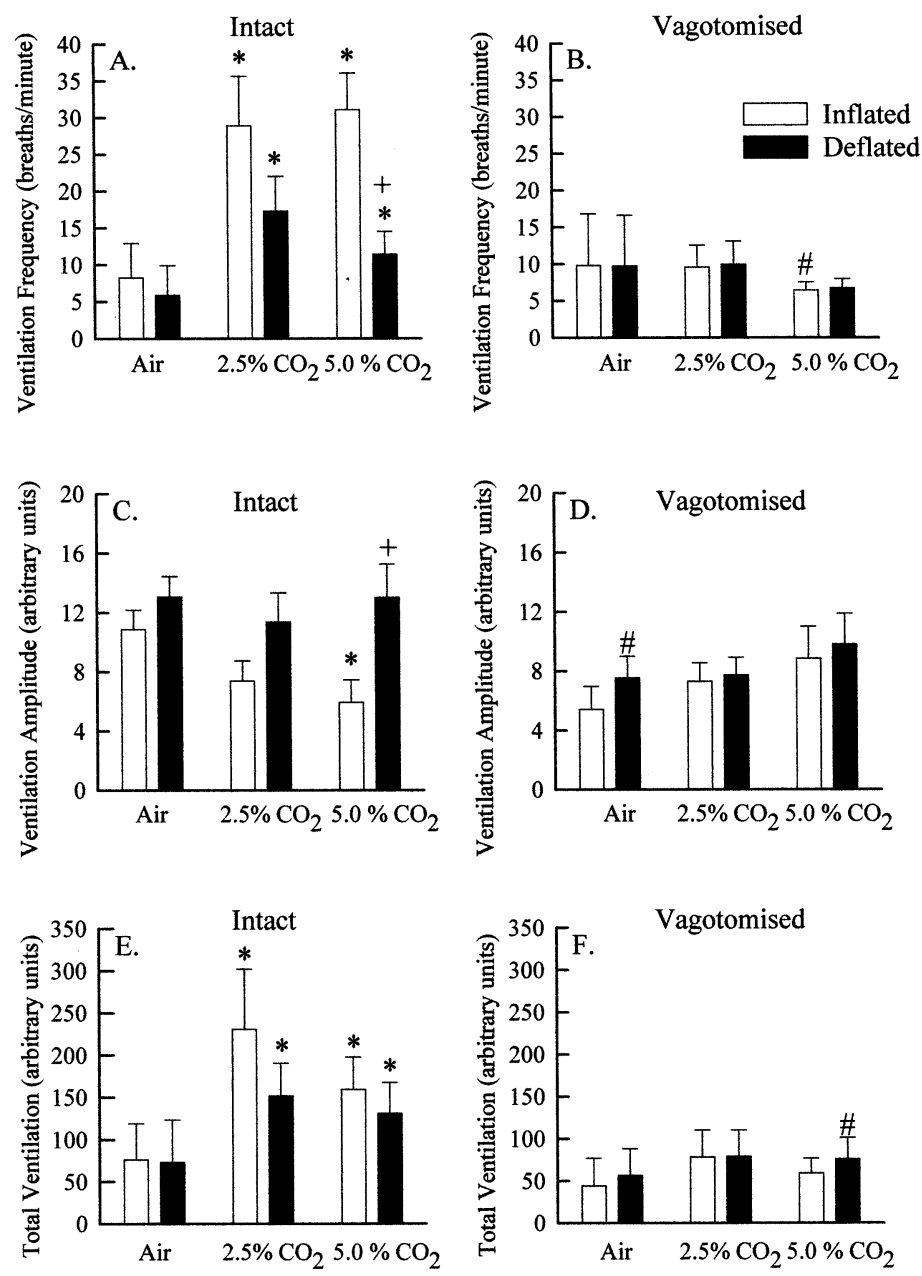

Fig. 3. The effects of UDV with air, $2.5 \% \mathrm{CO}_{2}$, and $5.0 \% \mathrm{CO}_{2}$ on absolute breathing frequency (breaths min ${ }^{-1}$; a and b), breathing amplitude (arbitrary units, c and d) and total ventilation (arbitrary units; e and f) before (a, c and e) and after (b, d and f) pulmonary vagotomy. The open bars represent a state of lung inflation while the solid bars represent a state of lung deflation. The data are shown as the mean \pm 1 S.E.M. An asterisk $(*)$ represents a significant difference during $\mathrm{UDV}^{*}$ with $\mathrm{CO}_{2}$, compared to air. A plus sign $(+)$ represents a significant difference between the inflated and deflated states for any given UDV gas mixture. A number sign (\#) represents a difference between the intact and vagotomised values for any given UDV gas mixture and inflation/deflation state.

$\mathrm{CO}_{2}$. Following pulmonary vagotomy (Fig. 3B), there was no increase in ventilation frequency during UDV with $\mathrm{CO}_{2}$ (compared to air). Absolute frequency was also unaffected by the state of lung inflation/deflation following vagotomy. Although there was a trend for absolute frequency to decrease following vagotomy, this decrease was only statistically significant during ventilation with $5.0 \% \mathrm{CO}_{2}$ with the lungs inflated.
The effects of $\mathrm{CO}_{2}$, lung inflation/deflation and pulmonary vagotomy on ventilation amplitude are illustrated in Fig. 3C and D. With the pulmonary vagi intact, ventilation with $5.0 \%$, but not $2.5 \%, \mathrm{CO}_{2}$ caused a significant decrease in ventilation amplitude when the lungs were inflated, but not deflated (Fig. 3C). During UDV with 5.0\% $\mathrm{CO}_{2}$ ventilation amplitude was greater when the lungs were deflated. Following pulmonary vago- 
tomy, there was no effect of $\mathrm{CO}_{2}$ or lung inflation/deflation on ventilation amplitude (Fig. 3D).

Fig. 3E illustrates that total ventilation increased during UDV with both 2.5 and $5.0 \% \mathrm{CO}_{2}$, with the lungs inflated or deflated, before pulmonary vagotomy. This increase in total ventilation was mediated exclusively by an increase in ventilation frequency as amplitude actually decreased as the animals were made hypercapnic (Fig. 3A, C). Following vagotomy (Fig. 3F) there was no effect of hypercapnia on total ventilation with levels, in general, being less than those before vagotomy.

Fictive breath duration (data not shown) was approximately $0.3 \mathrm{sec}$ and was unaltered by $\mathrm{CO}_{2}$ or lung inflation/deflation, regardless of whether the pulmonary vagi were intact or the animal was vagotomised.

\subsubsection{Effects of $\mathrm{CO}_{2}$, lung inflation/deflation and pulmonary vagotomy on breathing pattern}

3.1.4.1. Predominant effects of lung inflation/ deflation and pulmonary vagotomy. The effects of $\mathrm{CO}_{2}$, lung inflation/deflation and pulmonary vagotomy on breathing pattern are reported in Figs. 4-6. Fig. 4 illustrates the predominant effect of chronic lung inflation and deflation when the animals were ventilated with $5.0 \% \mathrm{CO}_{2}$ with the pulmonary vagus intact. In this case, when the lungs were deflated (outflow pressure $0 \mathrm{cmH}_{2} \mathrm{O}$ ) fictive breathing occurred in an episodic pattern. When the lungs were inflated (outflow pressure 4 $\mathrm{cmH}_{2} \mathrm{O}$ ) the episodic pattern disappeared and was replaced with one of continuous breathing. This effect was reversible as demonstrated by a subsequent deflation (arrow, lower panel) which abolished the continuous breathing and restored the episodes.

Table 2 illustrates the predominance of the various types of breathing patterns (apnea, continuous or episodic) exhibited under the conditions of UDV, lung inflation/deflation with the pulmonary vagi intact or transected. Generally, with the pulmonary vagi intact and UDV with $\mathrm{CO}_{2}$, lung deflation tended to make the animals breath in episodes while inflation favoured continuous breathing. During UDV with air, inflation tended to favour a state of apnea rather than continuous breathing. For example, during UDV
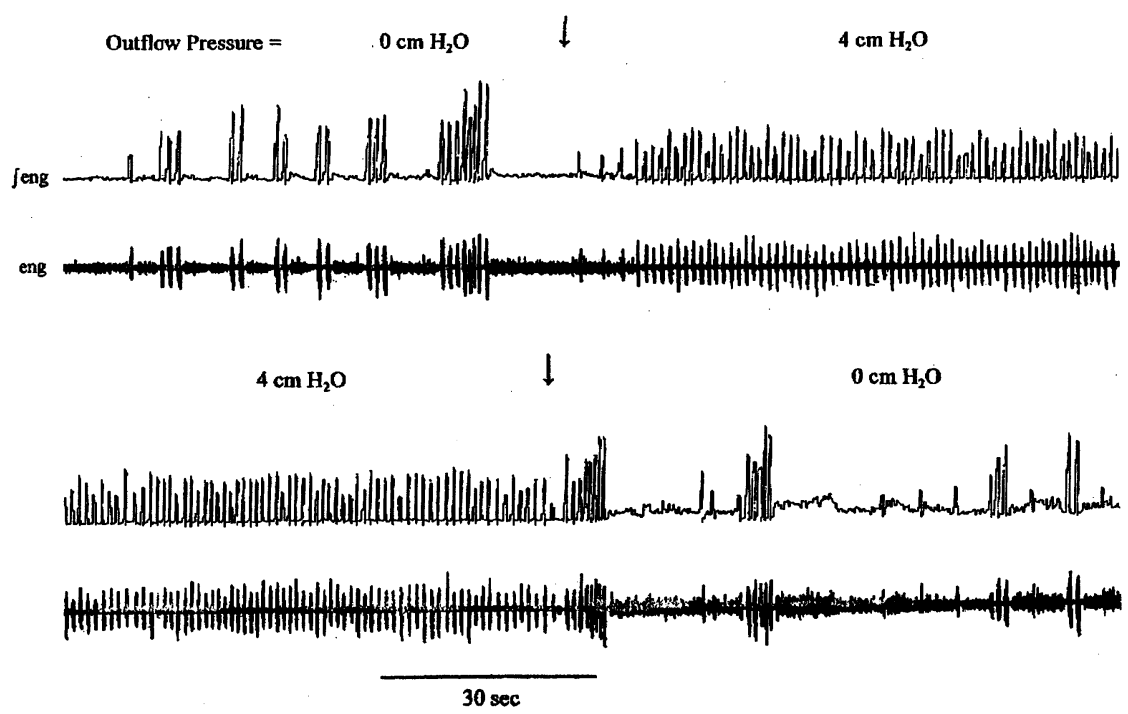

Fig. 4. The effects of lung inflation and deflation in a toad uni-directionally ventilated with $5.0 \% \mathrm{CO}_{2}$. In both panels, the upper trace represents the integrated nerve signal ( $\int \mathrm{eng}$ ) while the lower trace represents the raw nerve signal (eng). In this figure the lungs were initially deflated (left side of the upper panel) before inflation (at the arrow in the upper panel and continued in the lower panel). At the point marked by the arrow in the lower panel the lungs were once again deflated. Note that lung inflation produced a pattern of continuous breathing while deflation caused the expression of an episodic breathing pattern. 

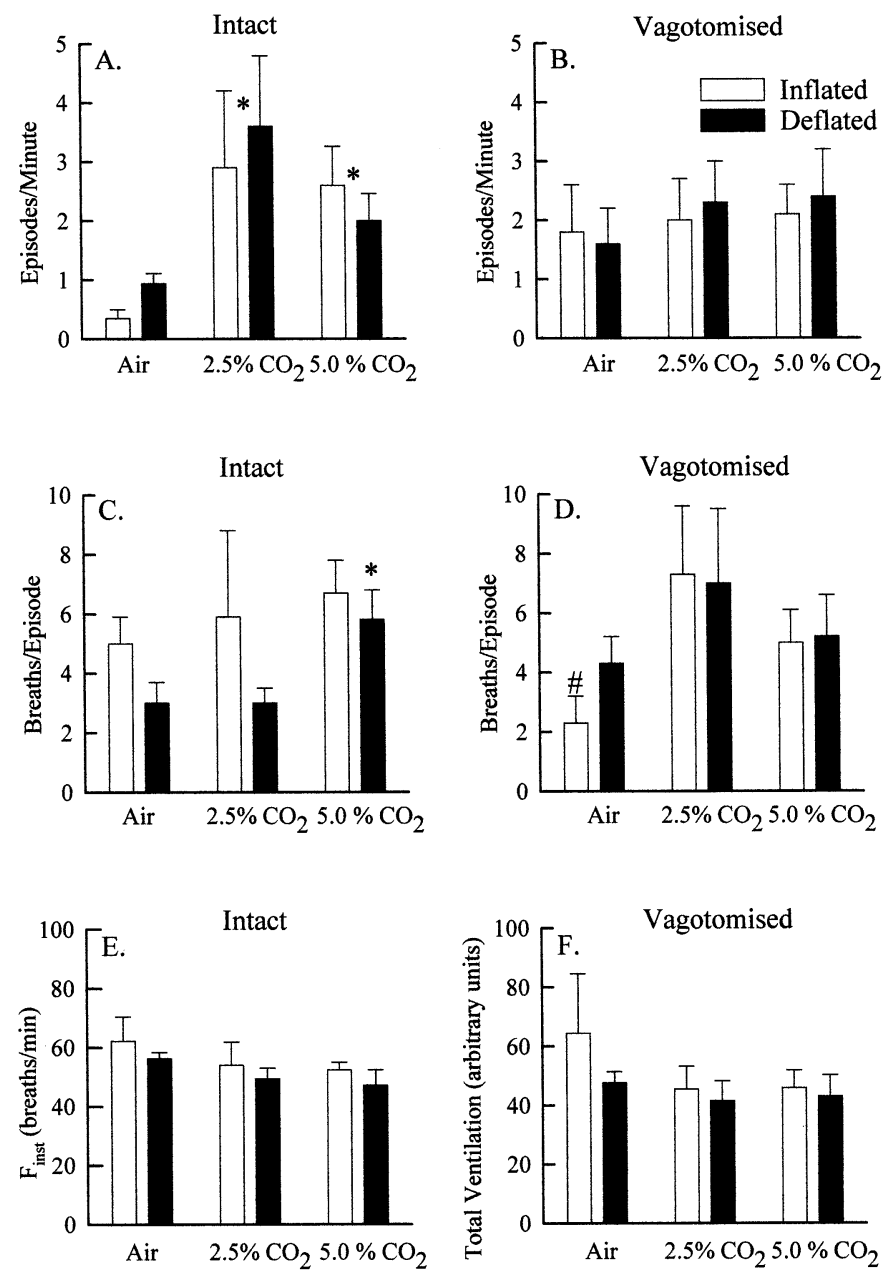

Fig. 5. The effects of UDV with air, 2.5\% $\mathrm{CO}_{2}$, and $5.0 \% \mathrm{CO}_{2}$ on the number of episodes per min (a and $\mathrm{b}$ ), the number of breaths per episode (c and d) and the instantaneous frequency of breathing in the episodes (breaths $\min ^{-1}$; e and f) before (a, c and e) and after ( $b, d$ and $f$ ) pulmonary vagotomy. The open bars represent a state of lung inflation while the solid bars represent a state of lung deflation. The data are shown as the mean \pm 1 S.E.M. An asterisk (*) represents a significant difference during UDV with $\mathrm{CO}_{2}$, compared to air. A plus sign (+) represents a significant difference between the inflated and deflated states for any given UDV gas mixture. A number sign (\#) represents a difference between the intact and vagotomised values for any given UDV gas mixture and inflation/deflation state.

with $5.0 \% \mathrm{CO}_{2}$, with the lungs inflated, no animals exhibited apnea while 5 of 12 showed episodic breathing and 7 of 12 showed continuous breathing. When the lungs were deflated, 11 of 12 animals exhibited episodic breathing while only one remained a continuous breather. Following pulmonary vagotomy, there was a greater tendency for all of the animals to breath in episodes when the lungs were both inflated and deflated such that the act of inflation/deflation did not influence the type of breathing pattern. For example, during UDV with $5.0 \% \mathrm{CO}_{2}$, all 9 animals exhibited episodic breathing and none displayed apnea or continuous breathing.

\subsubsection{Predominant effects of $\mathrm{CO}_{2}$ and pulmonary} vagotomy. Fig. 5 illustrates the number of episodes per minute (Fig. 5A, B), breaths per 
episode (Fig. 5C, D) and the instantaneous breathing frequency during fictive breathing episodes (Fig. 5E, F) in those cases where episodic breathing occurred. The small number of animals that exhibited episodic breathing under certain conditions (see Table 2), confounded an appropri- ate statistical analysis. However, subjectively there was no apparent effect of lung inflation or deflation on the frequency of breathing episodes. Thus in order to statistically demonstrate that increasing the $\mathrm{CO}_{2}$ concentration in the UDV gas mixture caused an increase in the frequency of

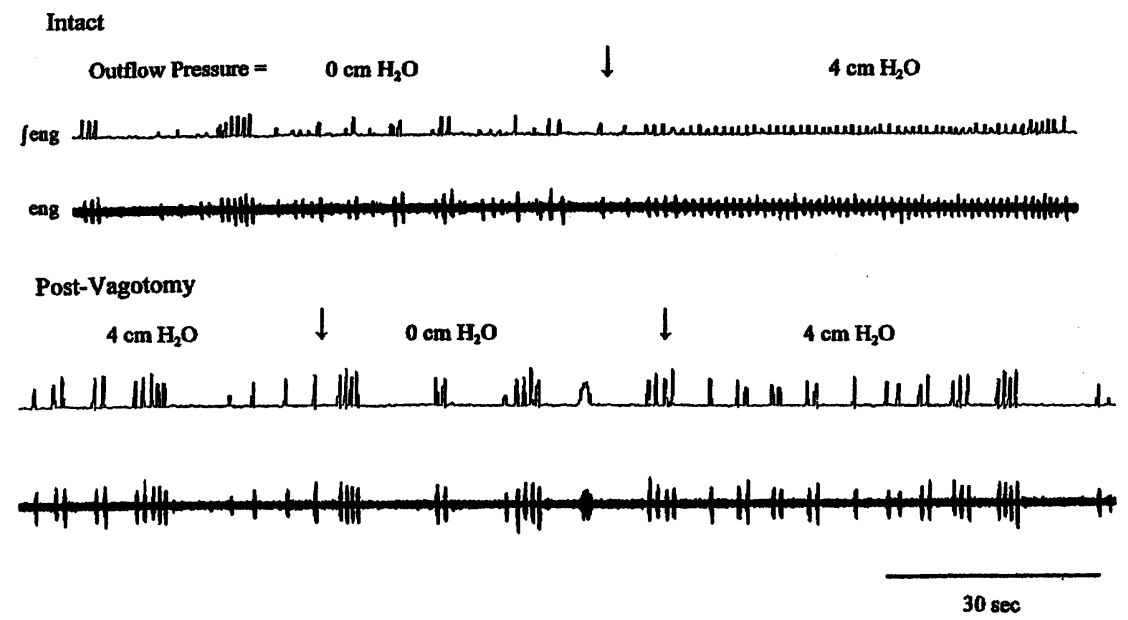

Fig. 6. The effects of rapid lung inflation and deflation in a toad uni-directionally ventilated with $5.0 \% \mathrm{CO}_{2}$, before (Upper pair of traces) and after (Lower pair of traces) pulmonary vagotomy. In both panels, the upper trace represents the integrated nerve signal ( $\int$ eng) while the lower trace represents the raw nerve signal (eng). Note that before vagotomy (upper panel), lung inflation produced a pattern of continuous breathing with small breaths from an episodic pattern with larger breaths in the deflated state. After vagotomy (lower panel), rapid lung inflation/deflation had no effect on the breathing pattern.

Table 2

The number of animals exhibiting, as the predominant breathing pattern, either apnea, continuous breathing or episodic breathing during the various combinations of inflation and UDV gas mixture

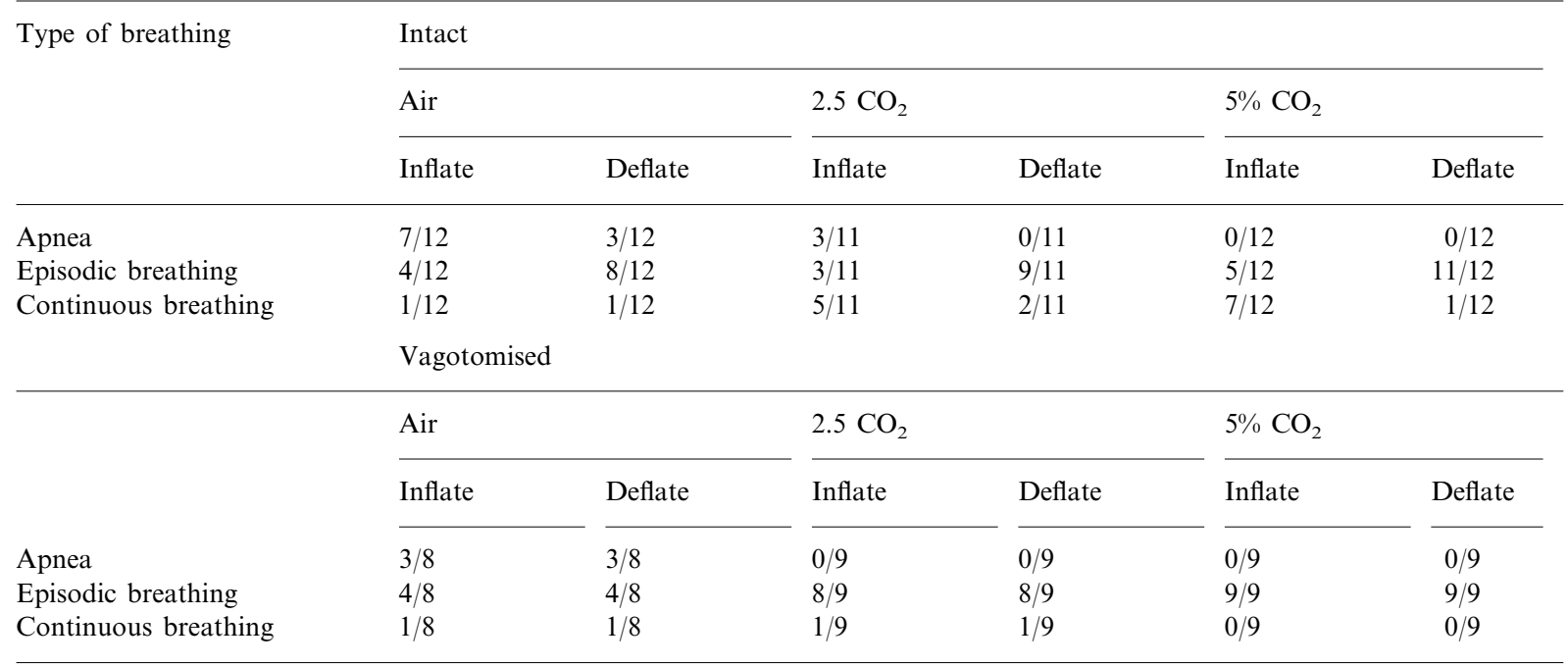


breathing episodes, the data from the inflated and deflated states have been combined. In this case it becomes evident that the frequency of episodes increases (Fig. 5A) when the UDV gas mixture contained $\mathrm{CO}_{2}$ in intact animals. Following transection of the pulmonary vagi, UDV with $\mathrm{CO}_{2}$ did not cause an increase in the frequency of episodes (Fig. 5B).

In the intact animals the number of breaths per episode increased during UDV with $5.0 \% \mathrm{CO}_{2}$ when the lungs were deflated, but not in any other case (Fig. 5C). This increase was abolished following vagotomy (Fig. 5D).

In contrast to the effects of $\mathrm{CO}_{2}$ and inflation/ deflation on absolute ventilation frequency, neither treatment had any affect on the instantaneous frequency of breathing in episodes regardless of whether the pulmonary vagi were intact (Fig. 5E) or the animals were vagotomised (Fig. 5F).

\subsubsection{Rapid lung inflation/deflation. Fig. 6 shows} the effects of rapid inflation and deflation before and following pulmonary vagotomy. With the vagi intact (Fig. 6A), lung inflation (arrow) caused a change from episodic breathing to continuous breathing. However, following pulmonary vagotomy (Fig. 6B), lung deflation (first arrow) and inflation (second arrow) did not affect the pattern of breathing with the majority of the breaths occurring in episodes rather than in a continuous pattern (also see Table 2).

\subsubsection{Cardiovascular variables}

Neither different UDV gas mixtures, lung inflation/deflation or pulmonary vagotomy had any affect on arterial blood pressure or heart rate (data not shown). Under all conditions, blood pressure varied between 40 and $50 \mathrm{cmH}_{2} \mathrm{O}$ while heart rate remained constant at $\approx 40$ beats $\min ^{-1}$.

\subsection{In vitro experiments}

\subsubsection{Characteristics of fictive ventilatory bursts}

Fig. 7 illustrates examples of fictive breathing generated by the same brainstem in situ and the following day, in vitro. Fig. 7A shows an episodic pattern of breathing in situ while Fig. 7B shows episodic breathing from the same brain in vitro. It is evident from this figure that fictive breath duration was reduced in vitro compared to in situ. Indeed, in situ, breath duration was $\approx 0.3 \mathrm{sec}$ (see above) while in vitro the duration was approximately half this value (Fig. 9C). Although the duration of the bursts differed, their shape was the same in situ (Fig. 7C) and in vitro (Fig. 7D), with both preparations exhibiting fictive breaths that displayed both an incrementing and decrementing phase.

Fig. 7E illustrates in vitro discharge consisting of single breaths (e.g. asterisk), a breathing episode and high frequency, low amplitude fictive buccal oscillations (e.g. arrow). These fictive buccal oscillations were also observed, in situ, predominantly during UDV with air and occasionally with $2.5 \% \mathrm{CO}_{2}$. The in vitro preparation also produced other motor outputs aside from fictive breaths. One of the more common types is illustrated in Fig. 7F with this burst beginning abruptly and then slowly decrementing.

Unlike the in situ preparation in which fictive breathing was often observed to occur in episodes, only four of the in vitro preparations exhibited episodes of fictive breathing regardless of the superfusate $\mathrm{pH}$. An example of in vitro motor output indicative of fictive breathing episodes is shown in Fig. 8. Note that on several occasions (Fig. 8A, B and C) the fictive breaths were accompanied by an increase in the 'background' level of discharge from the trigeminal nerve root. This phenomenon was not observed in situ.

\subsubsection{Effects of altering superfusate $p H$ on fictive ventilation}

Decreasing the $\mathrm{pH}$ of the superfusate from 8.0 to 7.6 did not alter any of the variables associated with fictive breathing in vitro (Fig. 9). As such, in all preparations, the absolute frequency of ventilation (Fig. 9A; dotted line) and the duration (Fig. 9C) of the fictive breaths were unaffected by $\mathrm{pH}$ changes. Additionally, in the four preparations that displayed episodic fictive breathing, $\mathrm{pH}$ did not affect the instantaneous breathing frequency in the episodes (Fig. 9B) nor the episode frequency (Fig. 9D) or breaths per episodes (Fig. 

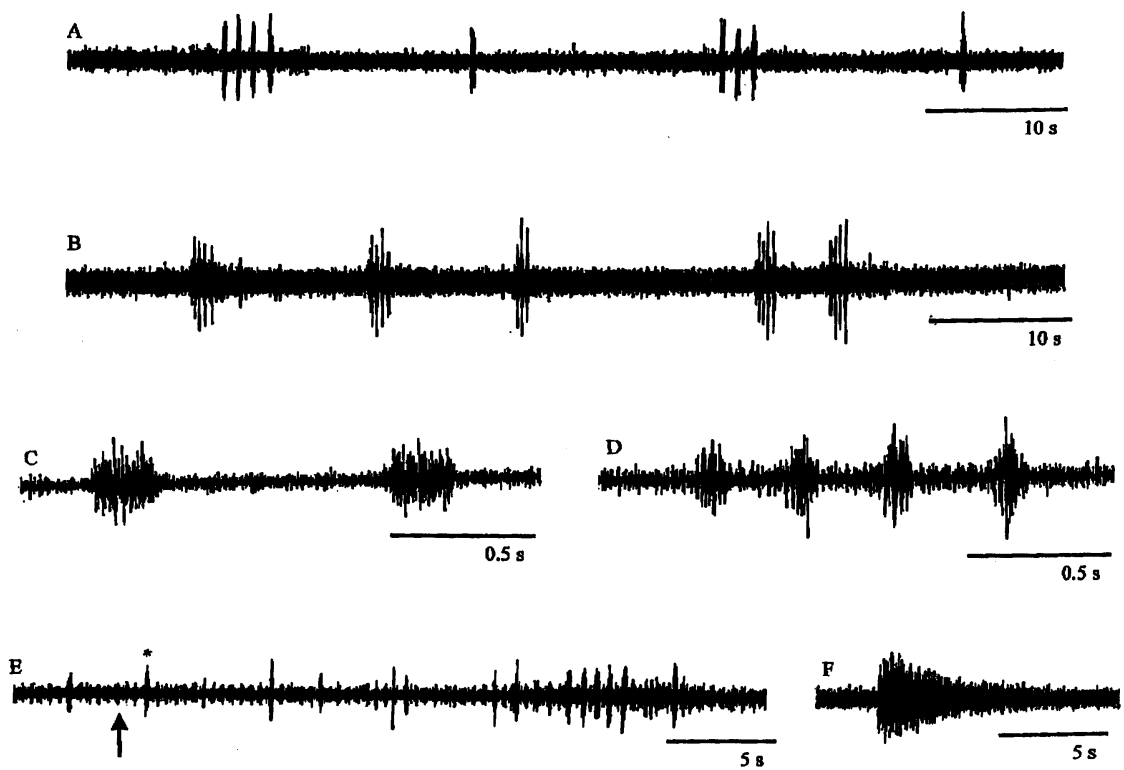

Fig. 7. Trigeminal nerve discharge recorded from the same B. marinus brainstem in situ and in vitro, illustrating the effects of progressive reduction of the preparation on the discharge pattern. (A) Fictive breathing recorded in situ (lungs deflated, UDV with $2.5 \% \mathrm{CO}_{2}$ ) showing breathing episodes and single breaths. (B) Nerve discharge recorded in vitro ( $\mathrm{pH} 7.8$ ). (C) Two breaths from the episodes illustrated in panel A (in situ) shown on an expanded time scale. (D) Four breaths from the episodes in panel B (in vitro) shown on an expanded time scale. (E) In vitro discharge illustrating single breaths (e.g. asterisk), a breathing episode and high frequency, low amplitude fictive buccal oscillations (e.g. arrow). (F) An abrupt decrementing burst ('Type B', gasp-like; Reid and Milsom 1998) recorded in vitro.

9E). The absolute frequency of ventilation was greater in the four preparations that exhibited an episodic pattern of fictive breathing (Fig. 9A; solid line) compared with the non-episodic preparations (Fig. 9B; dashed line).

\section{Discussion}

The results of this study demonstrate the crucial role of pulmonary vagal (pulmonary stretch receptor, PSR) feedback in modulating the respiratory response to hypercapnia in $B$. marinus. Specifically, input from the pulmonary vagi plays a role in the integration of $\mathrm{CO}_{2}$ chemosensory information and enhances the increase in ventilation frequency during hypercapnia. The breathing pattern is also dependent upon vagal feedback from the lungs. Lung deflation and pulmonary vagotomy favour an episodic breathing pattern composed of large breaths. Inflation biases the system towards apnea at low levels of respiratory drive and a continuous pattern of smaller breaths at higher levels of respiratory drive.

\subsection{Overall effects of pulmonary vagotomy on resting ventilation}

In the current study, pulmonary vagotomy did not change breathing frequency when the animals were ventilated with air. This is similar to the effect of vagotomy on breathing in unanaesthetised, decerebrate, paralysed (in situ) Rana catesbeiana ventilated with $1.7 \% \mathrm{CO}_{2}$ (Kinkead and Milsom, 1997), and intact bullfrogs breathing air (Kinkead and Milsom, 1996). On the other hand, Kogo et al. (1994) found that ventilation frequency decreased in $R$. catesbeiana, in situ, following pulmonary vagotomy during ventilation with air.

Pulmonary vagotomy caused fictive ventilation amplitude to decrease by $\approx 50 \%$ in this study 
during ventilation with air. Kogo et al. (1994) also report a decrease in fictive ventilation amplitude following vagotomy, while Kinkead and Milsom (1996) observed an increase in ventilation amplitude following vagotomy in intact (i.e. not decerebrate or paralysed) bullfrogs.

Thus the effect of vagotomy on resting ventilation, both frequency and amplitude, appears to vary for reasons that are not clear. Regardless, the fact that the effects of vagotomy can be so varied and dependent on factors such as the level of reduction of the preparation, the state of lung
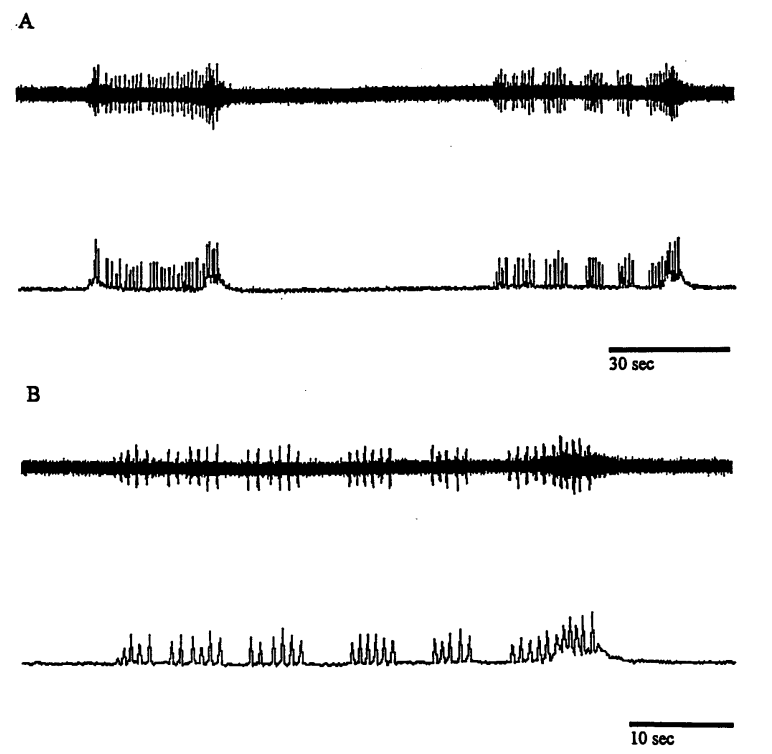

C
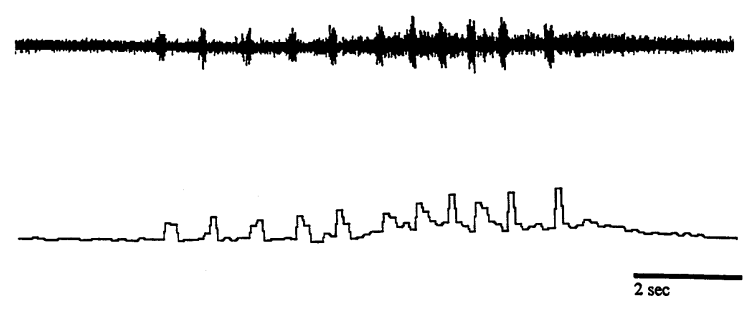

Fig. 8. (A) Several patterns of episodic motor output (fictive breathing) recorded from the trigeminal (V) nerve root in vitro $(\mathrm{pH} 7.8)$. Note that on three occasions, the fictive breathing was accompanied by an increase in the background level of discharge. (B) The last six individual episodes of fictive breathing illustrated in (A). Note that in the middle of the last episode the background level of discharge began to increase. (C) The last episode from parts $\mathrm{A}$ and $\mathrm{B}$ shown on an expanded time scale.
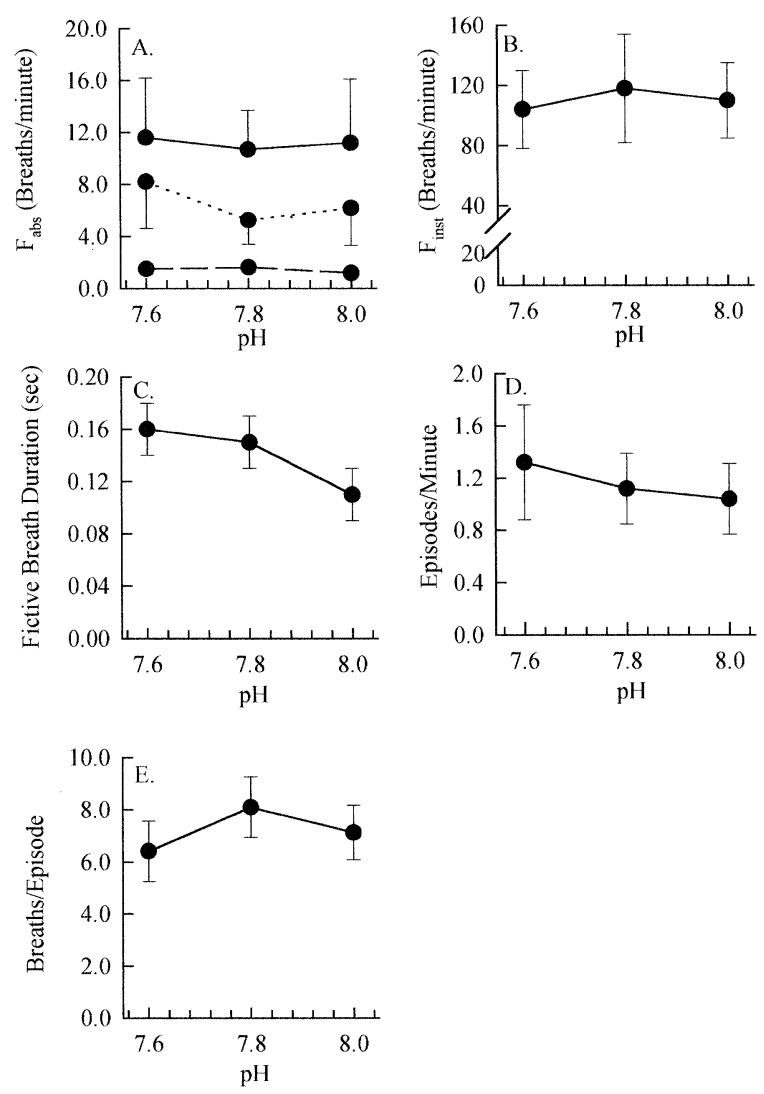

Fig. 9. The effect of altering superfusate $\mathrm{pH}$ (in vitro) on (A) The absolute frequency of breathing $\left(F_{\text {abs }}\right.$; breaths $\left.\min ^{-1}\right)$. (B) The instantaneous frequency of fictive breaths within episodes $\left(F_{\text {inst }}\right.$; breaths $\min ^{-1}$ ) in the four preparations that exhibited an episodic pattern of fictive breathing. (C) Fictive breath duration (sec). (D) The number of fictive breathing episodes per minute and (E) The number of breaths per episode. The data are shown as the mean \pm 1 standard error of the mean (S.E.M.).

inflation/deflation, and the level of chemoreceptor drive, supports the notion that the integration of mechanoreceptor input and chemical drive to produce breathing is a complex process in amphibians.

\subsection{Effects of vagotomy on $\mathrm{CO}_{2}$ chemosensitivity}

In this study, all increases in total ventilation during hypercapnia were mediated by increases in ventilation frequency rather than ventilation amplitude. Indeed, when the lungs were inflated, 
there was a decrease in ventilation amplitude with progressive hypercapnia. This is consistent with observations from similar in situ preparations of the toad (Wang et al., 1999) and the American bullfrog (Kinkead and Milsom, 1994, 1997). The observation that there are separate respiratory related sites involved in regulating ventilation amplitude and frequency in the bullfrog (McLean et al., 1995b) suggests that there may be an anatomical basis underlying the independent modulation of respiratory rate and amplitude.

The increase in ventilation frequency during hypercapnia was mediated by an increase in the frequency of breathing episodes in some animals and a switch to continuous breathing in others. This observation is consistent with the observations in the bullfrog made by Kinkead and Milsom (1994, 1996).

Following vagotomy, there no longer was a hypercapnia-induced increase in breathing frequency. There were no changes in either the frequency of episodes or the number of breaths per episode. Thus, when hypercapnia was induced by UDV with 2.5 or $5.0 \% \mathrm{CO}_{2}$, the normal increase in ventilation frequency was abolished following bilateral transection of the pulmonary vagi. It would appear, therefore, that integration of vagal (PSR) feedback with chemosensory information plays an integral role in determining the ventilatory response to $\mathrm{CO}_{2}$ in this species. Currently the nature, mechanisms and anatomical loci of this integration are not known. At present the literature regarding central locations involved in breathing rhythm and pattern generation in anurans is sparse. McLean et al. (1995b) described regions within the bullfrog ( $R$. catesbeiana) brainstem that are involved in modulating breathing amplitude and frequency while Milsom et al. (1997) reported that central descending inputs are critical for the clustering of breaths into discrete episodes. Kinkead et al. (1997) described the nucleus isthmi, a mesencephalic structure, as an integrative center involved in regulating overall levels of respiratory drive. It is possible that the nucleus isthmi, or a similar integrative center, is responsible for incorporating vagal (PSR) feedback with peripheral and/or central chemosensory informa- tion to produce the hypercapnic ventilatory response.

\section{3. $\mathrm{CO}_{2}$ chemosensitivity in situ versus in vitro}

In the in vitro brainstem-spinal cord preparation, altering the $\mathrm{pH}$ of the superfusate to mimic changes in arterial $\mathrm{pH}$ during UDV with 2.5 and $5.0 \% \mathrm{CO}_{2}$ did not produce an increase in ventilation frequency. Indeed, the $\mathrm{pH}$ changes in vitro were without effect on any of the variables associated with fictive breathing. This is not surprising given that $\mathrm{CO}_{2}$ chemosensitivity, in most in vitro preparations of the brainstem-spinal cord from the American bullfrog, compared with less reduced preparations, is substantially diminished (McLean et al., 1995a; Torgerson et al., 1997), or entirely absent (Reid and Milsom, 1998). Thus, the lack of effect was likely not due to the limited $\mathrm{pH}$ range. Indeed, based on the vagotomised preparation in this study, and the results of other studies (e.g. Kinkead and Milsom, 1996), one would predict that fictive breathing frequency in the in vitro brainstem-spinal cord preparation would be insensitive to changes in superfusate $\mathrm{CO}_{2} / \mathrm{pH}$ since there is no functional vagal (PSR) feedback in this preparation.

The absolute frequency of ventilation in the episodic in vitro preparations was $\approx 12$ breaths per min regardless of the $\mathrm{pH}$. This was similar to the less reduced preparation in which the vagal (PSR) feedback was abolished by vagotomy or reduced by lung deflation. The absolute frequency in situ before vagotomy during ventilation with $\mathrm{CO}_{2}$ when the lungs were deflated, and following vagotomy under all conditions was also about ten breaths per min. This suggests the possibility that the episodic in vitro preparations are breathing at a maximal rate when the $\mathrm{pH}$ is 8.0 and are incapable of increasing breathing frequency when the $\mathrm{pH}$ is lowered without vagal feedback. Further, it is also possible that some, as yet undescribed, central descending influence (positive or negative) is absent or non-functional in both the in situ and in vitro preparations which, in turn, prevents the increase in breathing in response to changes in $\mathrm{P}_{\mathrm{CO}_{2}} / \mathrm{pH}$ when there is no feedback from PSR. 


\subsection{Breathing pattern}

One of the major observations of this study was that lung inflation caused small breaths to occur at a high frequency at high levels of respiratory drive and apnea at low levels of respiratory drive. Deflation, for the most part, caused larger breaths to occur at a lower frequency and also in episodes. It is possible that when the lungs are deflated, the animals are trying to inflate the lungs with larger breaths that occur in episodes indicative of lung inflation cycles. It is also possible that when respiratory drive is low, lung inflation inhibits breathing but when respiratory drive is high, the small breaths that occur continuously are an attempt to exhale so that all of the motor output from the trigeminal nerve is expiratory in nature. In Rana, lung inflation has been shown to both inhibit (De Marneffe-Foulon, 1962) and stimulate (Kinkead and Milsom, 1997) ventilation. In an in situ preparation of the toad, while lung inflation abolished large amplitude breaths, it also gave rise to small amplitude bursts of fictive discharge that were indistinguishable from buccal oscillations (Wang et al., 1999). These authors concluded that these bursts of discharge represented fictive attempts at exhalation rather than an increase in the frequency of non-ventilatory buccal oscillations. The results of the present study are consistent with this conclusion and further suggest that one needs to determine whether ventilatory activity is buccal or lung related and inspiratory or expiratory in nature when attempting to ascribe an inhibitory or stimulatory role to lung inflation/deflation.

Although all of the in situ preparations exhibited episodic breathing under one condition or another, only four of the in vitro preparations displayed this type of pattern. Once an isolated brainstem-spinal cord began to exhibit episodic breathing, it continued in this fashion for the entire experiment. If a preparation was nonepisodic from the beginning, episodic breathing could not be induced. The reasons for this are not clear as all preparations lack descending influences from higher centres and all feedback from the periphery. Thus, it would appear that while the brainstem in vitro is capable of generating breathing episodes, in the absence of higher centres and vagal feedback, episodes can be rare.

\subsection{Lung inflation/deflation versus vagotomy}

In the current study, vagotomy had similar effects to lung deflation on breathing frequency but not ventilation amplitude. While breathing air, neither vagotomy nor deflation had an effect on breathing frequency while at higher levels of respiratory drive, breathing frequency decreased during lung deflation with the vagi intact and also following pulmonary vagotomy. In terms of breathing amplitude, however, while vagotomy caused a decrease in ventilation amplitude while the animals were breathing air, it had no effect on amplitude at higher levels of respiratory drive. Deflation, on the other hand, had no effect on breathing amplitude while the animals were breathing air but increased amplitude at higher levels of respiratory drive. The net effect was that total ventilation decreased under both situations. These results are similar to those obtained in the bullfrog by Kinkead and Milsom (1997) but are opposite to those obtained in other studies on the toad (Wang et al., 1999), and bullfrog (Kogo et al., 1994). De Marneffe-Foulon (1962) and Serbeniuk and Gurskaia (1987) also demonstrated that decreased pulmonary afferent activity stimulated ventilation in Rana while Shelton and Boutilier (1982) reported that lung deflation during spontaneous inflation tended to stimulate buccal pumping during the lung ventilation cycle in Xenopus. These latter studies are much like the situation in mammals where the effects of vagotomy usually are not the same as the effects of lung deflation. In mammals, vagotomy almost always decreases breathing frequency and increases tidal volume (as in most studies on Rana and Bufo) while lung deflation generally increases breathing frequency. The reasons for this are still not totally clear.

\section{Summary}

In conclusion, this study demonstrates a crucial role for vagal (pulmonary stretch receptor) feedback in modulating respiration and the respira- 
tory responses to hypercapnia in $B$. marinus. PSR input plays a key role in the integration of $\mathrm{CO}_{2}$ chemosensory information during hypercapnia and is important in determining the nature of the breathing pattern. There continue to be discrepancies between the effects of reducing versus eliminating vagal feedback on breathing pattern in both Bufo and Rana for reasons that are not yet clear.

\section{Acknowledgements}

Financial support was provided from the Natural Sciences and Engineering Research Council (NSERC) of Canada in the form of research and equipment grants to WKM and NHW. SGR was the recipient of an NSERC Post-Doctoral fellowship and a Research Fellowship from the College of Medicine, University of Saskatchewan.

\section{References}

Branco, L.G.S., Glass, M.L., Hoffman, A., 1992. Central chemoreceptor drive to breathing in unanesthetized toads, Bufo paracnemis. Respir. Physiol. 87, 195-204.

De Marneffe-Foulon, C., 1962. Contribution à l'étude du mechanisme et du contrôle des mouvements respiratoires chez Rana. Ann. Soc. R. Zool. Belg. 92, 81-132.

Galante, R.J., Kubin, L., Fishman, A.P., Pack, A.I., 1996. Role of chloride-mediated inhibition in respiratory rhythmogenesis in an in vitro brainstem of tadpole, Rana catesbeiana. J. Physiol. Lond. 492, 545-558.

Ito, F., Watanabe, S., 1962. Localisation and organisation of respiratory neurons in the brainstem of the toad, with reference to activities of slow motor system. Jpn. J. Physiol. $12,611-622$.

Kimura, N., Perry, S.F., Remmers, J.E., 1997. Strychnine eliminates reciprocation and augmentation of respiratory bursts of the in vitro frog brainstem. Neurosci. Lett. 224, $1-4$.

Kinkead, R., Milsom, W.K., 1994. Chemoreceptors and control of episodic breathing in the bullfrog (Rana catesbeiana). Respir. Physiol. 95, 81-98.

Kinkead, R., Filmyer, W.G., Mitchell, G.S., Milsom, W.K., 1994. Vagal input enhances responsiveness of respiratory discharge to central changes in $\mathrm{pH} / \mathrm{CO}_{2}$ in bullfrogs. $\mathrm{J}$. Appl. Physiol. 77, 2048-2051.

Kinkead, R., Milsom, W.K., 1996. $\mathrm{CO}_{2}$-sensitive olfactory and pulmonary receptor modulation of episodic breathing in bullfrogs. Am. J. Physiol. 270, R134-R144.
Kinkead, R., 1997. Episodic breathing in frogs: converging hypotheses on neural control of respiration in air breathing vertebrates. Amer. Zool. 37, 31-40.

Kinkead, R., Milsom, W.K., 1997. Role of pulmonary stretch receptor feedback in control of episodic breathing in the bullfrog. Am. J. Physiol. 272, R497-R508.

Kinkead, R., Harris, M.B., Milsom, W.K., 1997. The role of the nucleus isthmi in respiratory pattern formation in bullfrogs. J. Exp. Biol. 200, 1781-1793.

Kogo, N., Remmers, J.E., 1994. Neural organization of the ventilatory activity in the frog, Rana catesbeiana II. J. Neurobiol. 25, 1080-1094.

Kogo, N., Perry, S.F., Remmers, J.E., 1994. Neural organization of the ventilatory activity of the frog, Rana catesbeiana I. J. Neurobiol. 25, 1067-1079.

Kuhlmann, W.D., Fedde, M.R., 1979. Intrapulmonary receptors in the bullfrog: sensitivity to $\mathrm{CO}_{2}$. J. Comp. Physiol. 132A, 69-75.

Liao, G.-S., Kubin, L., Galante, R.J., Fishman, A.P., Pack, A.I., 1996. Respiratory activity in the facial nucleus in an in vitro brainstem of the tadpole, Rana catesbeiana. J. Physiol. Lond. 492, 529-544.

McLean, H.A., Kimura, N., Kogo, N., Perry, S.F., Remmers, J.E., 1995a. Fictive respiratory rhythm in the isolated brainstem of bullfrogs. J. Comp. Physiol. A. 176, 703713.

McLean, H.A., Perry, S.F., Remmers, J.E., 1995b. Two regions in the isolated brainstem of the frog that modulate respiratory-related activity. J. Comp. Physiol. A. 177, 145158.

Milsom, W.K., Jones, D.R., 1977. Carbon dioxide sensitivity of pulmonary receptors in the frog. Exp. Basel. 33, 11671168.

Milsom, W.K., 1991. Intermittent breathing in vertebrates. Annu. Rev. Physiol. 53, 87-105.

Milsom, W.K., Harris, M.B., Reid, S.G., 1997. Do descending influences alternate to produce episodic breathing? Respir. Physiol. 110, 307-317.

Reid, S.G., Milsom, W.K., 1998. Respiratory pattern formation in the isolated bullfrog (Rana catesbeiana) brainstemspinal cord. Respir. Physiol. 114, 239-255.

Sakakibara, Y., 1984a. The pattern of respiratory nerve activity in the bullfrog. Jpn. J. Physiol. 34, 269-282.

Sakakibara, Y., 1984b. Trigeminal nerve activity and buccal pressure as an index of total inspiratory activity in the bullfrog. Japn. J. Physiol. 34, 827-838.

Serbeniuk, T.S.V., Gurskaia, I.E., 1987. Role of the pulmonary mechanoreceptor apparatus in molding the natural respiration of the frog, Rana temporaria. Zhurnal Evoliutsionnoi Biokhimii i Fiziologii. 22, 548-554 in Russian.

Shelton, G., Boutilier, R.G., 1982. Apnoea in amphibians and reptiles. J. Exp. Biol. 100, 245-273.

Smatresk, N., Smits, A.W., 1991. Effects of central and peripheral chemoreceptor stimulation on ventilation in the marine toad, Bufo marinus. Respir. Physiol. 8, 32233238.

Torgerson, C.S., Gdovin, M.J., Remmers, J.E., 1997. Ontogeny of central chemoreception during fictive gill and 
lung ventilation in an in vitro brainstem preparation of Rana catesbeiana. J. Exp. Biol. 200, 2063-2072.

Wang, T., Taylor, E.W., Reid, S.G., Milsom, W.K., 1999. Lung deflation stimulates fictive ventilation in decerebrate, paralysed and unidirectionally ventilated toads (Bufo marinus). Respir. Physiol. 118, 181-191.

West, N.H., Topor, Z.L., van Vliet, B.N., 1987. Hypoxemic threshold for lung ventilation in the toad. Respir. Physiol. 70, 377-390.

West, N.H., Van Vliet, B.N., 1992. Sensory mechanisms regulating the cardiovascular and respiratory systems. In: Feder, M.E., Burggren, W.W. (Eds.), Environmental Physiology of the Amphibians. The University of Chicago Press, Chicago, IL, pp. 151-182. 